\title{
Characteristics and Risk Factors for Polycystic Ovarian Syndrome Among Females
}

\author{
Bakhtyar Kamal Muhammad \\ Anesthesia Department \\ Technical College of Health \\ Sulaimani Polytechnic University \\ Sulaimani, Iraq \\ Bakhtyar.talabany@spu.edu.iq
}

\section{Article Info \\ Volume 5 - Issue 1 - June 2020 \\ DOI: \\ 10.24017/science.2020.1.14 \\ Article history:}

Received : 29 March 2020

Accepted : 15 May 2020

\section{Keywords:}

Polycystic Ovarian

Syndrome,

Risk Factor,

Stress,

Fertility.

\begin{abstract}
Polycystic ovary syndrome (PCOS) is a major endocrinal syndrome may affect the female at adult ages. In polycystic ovary, the ovarian seen that are enlarged and the investigation may base on ultra-sonographic detection. Polycystic ovarian syndrome always represents a spectrum of syndrome rather than the diseases. Also clinically presented by polycystic on ovarian and generally demonstrated by reversible. 104 female patients were examined, 18 (17.3\%) of females were diagnosed with polycystic ovarian syndrome. The mean age was $24.62 \pm 7.32$ years (ranged from 15 month to 50 years-old). 17 (94.4\%) of women were less than 25 years-old p-value=0.03, hormonal abnormality was the most frequent symptoms in relation to polycystic ovarian syndrome $10(55.5 \%)$ and p-value $=0.001 .16(88.9 \%)$ of women experienced vaginal discharge $p$-value $=0.09$. In conclusion, one from six females is expected to experience polycystic ovarian syndrome. Young females are probably to be at a high risk for developing polycystic ovarian syndrome. Despite uncertain etiology of polycystic ovarian syndrome, marital status, stress or anxiety, doing a regular exercise and pregnancy are all related parameters to the incidence of polycystic ovarian syndrome. Additionally, Cases with high hormonal abnormality and vaginal excretion could be considerable indicators of polycystic ovarian syndrome.
\end{abstract}




\section{INTRODUCTION}

Polycystic ovarian disorder is a disorder characterized by oligo-menorrhoea, anovulation, hirsutism, overweight, and infertility in adult female with bilaterally enlarged and with cyst in ovaries. The basic biochemical abnormalities are highly producing of androgen and low rates of pituitary stimulating follicle hormone. These abnormalities were associated to primary ovary flawed as illustrated by excellent outcome from chunk resection of the ovarian. Recent concept of prognosis of polycystic ovarian syndrome is the irregular secreting stimulating hormone by pituitary gland.

Also, the polycystic ovarian syndrome is hyper-androgenic syndrome related to chronic oligoanovulatin and polycystic ovarian syndrome morphologies. Its clinical expressions may consist of menstrual irregularities, harbingers of androgen profusion, and overweight. Polycystic ovarian syndrome is correlated with a widened hazard of type 2 diabetes. Since the 1990, NIH subsidized conference on polycystic ovarian syndrome, it has converted enjoyed that the problem encircles a larger spectrum of signs and symptoms of ovarian dysfunction than those delineated by the initial diagnostic principles. It is now noticed that women with formal cycles and hyperandrogenism and/or polycystic ovaries may have the problem. It has again been noticed that some women with the disorder will have polycystic ovarian syndrome without clinical confirmation of androgen exuberance but will exhibit confirmation of ovarian dysfunction [1,2].

Polycystic ovarian syndrome associated with cognitive deterioration, such as abasements, other attitude, syndromes, metabolic muddles, predominantly insulin defiance and offsetting hyperinsulinemia, which is a responsible cofactors for alteration in androgen preparation and existence [3]. It has been reported that polycystic ovarian syndrome is due to the compounds combination with hereditary, environmental, and attitude factors [4]. Regarding to the National Institutes of Health (NIH), investigation benchmark predicted that 4 to 10 percent of female at adult ages go through polycystic ovary syndrome [5].

The prognosis of polycystic ovarian syndrome is alleviating not generally known. Previous study demonstrated that polycystic ovary syndrome could be associated with singlenucleotide poly-morphemes (SNPs) [6].

Oxidative stress was studied as a probability like factor in the prognosis of polycystic ovary syndrome, which was more common combination of endrcrinic syndrome and causative agents of infertility in females [7].

Overweight, a popular endocrine illness on the earth, were firstly isolated into visceral obesity and tangential obesity by ambiguous in 1956, and called central obesity and lowered body obesity. Innate obesity, also called celiac obesity, in which visceral adipose tissue are chiefly compile in the abdominal and apportioned widely on omentum and mesenterium, around entrails, and in skeletal muscles, could be regulated by the elevated waist grith. According to the innate obesity, tangential adipose tissue are chiefly comply under the peripheral skin, especially in backside and legs, also are mostly assessed by body mass index (BMI). About $42 \%$ of patients with polycystic ovary syndrome have the complexity of overweight. Abdominal adipose tissue is considered to be in relation with metabolic disorders and more significantly than subcutaneous adipose tissue. Diagnostic method of abdominal overweight has not been demonstrated yet, but the size and the density of internal fat demonstrated by electronic computer X- ray technique are often regarded as the base standard. However, waist girth is a simple and reliable criterion always applied to estimate obesity in the abdomen inside the clinic. Abdominal overweight is regarded as a common side effect of polycystic ovarian disorder, and the risk of abdominal overweight in polycystic ovarian syndrome in female ranged from $40 \%$ to $80 \%$ because of the differences of individual and nation. Body mass index is used as a popular criterion in clinic to evaluate obesity. However, about $50 \%$ of polycystic ovarian syndrome patients with normal body mass index still to abdominal overweight or obesity

Fatty body or over-weight affects more of the patients with polycystic ovarian syndromes [8]. 
Also polycystic ovarian syndromes can cause infertility due to alteration in rate of excretion and composition of the polymeric-hydrogel, cervical exudate which is important for sperm transport and appreciation. [9, 10].

In women with polycystic ovarian syndrome, especially in the presence abnormal cervical mucus/CVF (cervical vaginal fluid), can elevate the risk infertility, but this remains unclear due to limited published data.

In the previous study found that the average foramen size of the cervical excretion fibers could be decreased in polycystic ovary syndrome. Also another study demonstrated that any abnormality in composition of cervical secretion occur in polycystic ovarian syndrome [1].

Polycystic ovarian syndrome usually affect female but in rare condition affect male in less frequency. However, man not had ovary but occasionally affect (high rate of androgen and low rate of steroidal bind to globulin) and clinical manifestation of polycystic ovarian syndrome could be shown in men and they will be changed to steinleventhal disorder $[12,13]$. Evaluation of testosterone is approved in the all of the recent clinical instruction but another steroids, like andro-stenedione and dehydro-epiandrosterone suffer "DHEAS", were also be seen that benefit in investigation of polycystic ovarian syndrome and could be given further knowledge on metabolism risk-factors $[14,15]$.

\section{PATIENTS AND METHODS}

A cross sectional descriptive study is used for the current study and the study included two distinct parts, the first part of the study is to describe the demographic characteristic's adult females. The second part was to determine of magnitude, clinical presentation and outcome polycystic ovarian syndrome from August 2019 to January 2020.

The study is conducted in a privet Ultrasound center for ultra-sonographic investigation in Sulaimani city, were they have patients that referred from clinical and privet sector by a physicians.

Population for this study includes females that had abnormal condition in their reproductive system and visited to institutional or privet sector for investigation according to clinical signs and referred to privet situation for demonstration internal finding. The data collected from the patients focused on the clinical signs and ultra-sonographic finding, by using selfadministered questionnaire.

To achieve the objectives of this investigative work, a questionnaire was used to collect data from the participant. A personal interview was held for filling in the questionnaire. All interviews were conducted face to face. The questionnaire was based on the review of literature related to polycystic ovarian syndrome or female reproductive disorders. Pre-test was used in $5 \%$ of the sample size before the study to make sure that the data collecting sheet is capable of yielding the required data for the study and some modifications were done according to the results found and to find response from their families, especially girl's participant. A questionnaire approved by some of specialized physician and health care workers. A structured data collection sheet about polycystic ovarian syndrome was used to assess the characteristic of patients and some of factors related to polycystic ovarian syndrome, burn infection, microbial investigations, antibiotic sensitivity and outcomes. Clinical assessment of the wound: cause of burn, site affected, family history, stress, body weight, and regular exercise. Chronological data and observation were used by the researcher during the observation visits.

Data generated from this work were tabulated into Microsoft excel sheets and uploaded to SPSS (Statistical Package for Social Sciences) version 22.0 software. Percentage / correlating were used for measure and analysis. Means, standard deviation and confidence interval to be used to summarize continuous variables whereas categorical variables to be summarized in form of proportions and frequency tables Chi-square $(\chi 2)$ test was used to test for significance of associations between the predictor and outcome variables in the categorical variables to find an outcome related to health issues. T-test used for comparison two means. Statistical comparison of microbial isolates and their resistance pattern was done. $\mathrm{P}$-value of $<0.05$ was 
considered as statistically significant cutoff. The generated data is compiled by frequency tables, charts, and figures. EndNote program and Vancouver style was used for references citation.

\section{RESULTS}

A total of 104 females participants were studied, 57 (54.8\%) of them were married and 45 (45.2\%) of women were unmarried. $77(74.0 \%)$ of them were from rural residency and 27 (26.0\%) from urban residency. Majority of them were <25 years-old 81 (77.9\%), followed by 25-40 years $17(16.3 \%)$. The mean age was $24.62 \pm 7.32$ years (ranged from 15 month to 50 years-old). 66 (63.3\%) of females have no family history of polycystic ovaries syndrome. 73 (29.8\%) of women do regular exercises. 67 (64.4\%) of them has a normal body weight, overweight and underweight were $19(18.3 \%)$ and $18(17.3 \%)$ resepectively.79 $(76.0 \%)$ of females have no child. While, $18(17.3 \%)$ and 7 (6.7\%) of women have 1-4 child and more than 4-child respectively (table 1 ).

Table 1: Demographic personality of the participants

\begin{tabular}{|c|c|c|}
\hline Demographic personality & Number & Percent \\
\hline \multicolumn{3}{|l|}{ Marital states } \\
\hline Married & 57 & 54.8 \\
\hline Not married & 45 & 45.2 \\
\hline \multicolumn{3}{|l|}{ Residency } \\
\hline Rural & 77 & 74.0 \\
\hline Urban & 27 & 26.0 \\
\hline \multicolumn{3}{|l|}{ Age group } \\
\hline$<25$ & 81 & 77.9 \\
\hline $25-40$ & 17 & 16.3 \\
\hline$>40$ & 6 & 5.8 \\
\hline \multicolumn{3}{|l|}{ Family history with polycystic ovary } \\
\hline $\begin{array}{cc} & \text { Yes } \\
\end{array}$ & 38 & 36.5 \\
\hline No & 66 & 63.5 \\
\hline \multicolumn{3}{|l|}{ Do regular exercises } \\
\hline Yes & 31 & 70.2 \\
\hline No & 73 & 29.8 \\
\hline \multicolumn{3}{|l|}{ Body weight } \\
\hline Normal & 67 & 64.4 \\
\hline Overweight & 19 & 18.3 \\
\hline Underweight & 18 & 17.3 \\
\hline \multicolumn{3}{|l|}{ Number of Child } \\
\hline ( & 79 & 76.0 \\
\hline $1-4$ & 18 & 17.3 \\
\hline$>4$ & 7 & 6.7 \\
\hline Mean age (SD) & & \\
\hline
\end{tabular}

From 104 patients were investigated, $88(84.6 \%)$ were with no symptoms, 12 (11.6) were had hormonal abnormality and 4 (3.8\%) of them had hirsutism (Figure 2).18 (17.3\%) of them were with polycystic ovaries syndromes (figure1). 


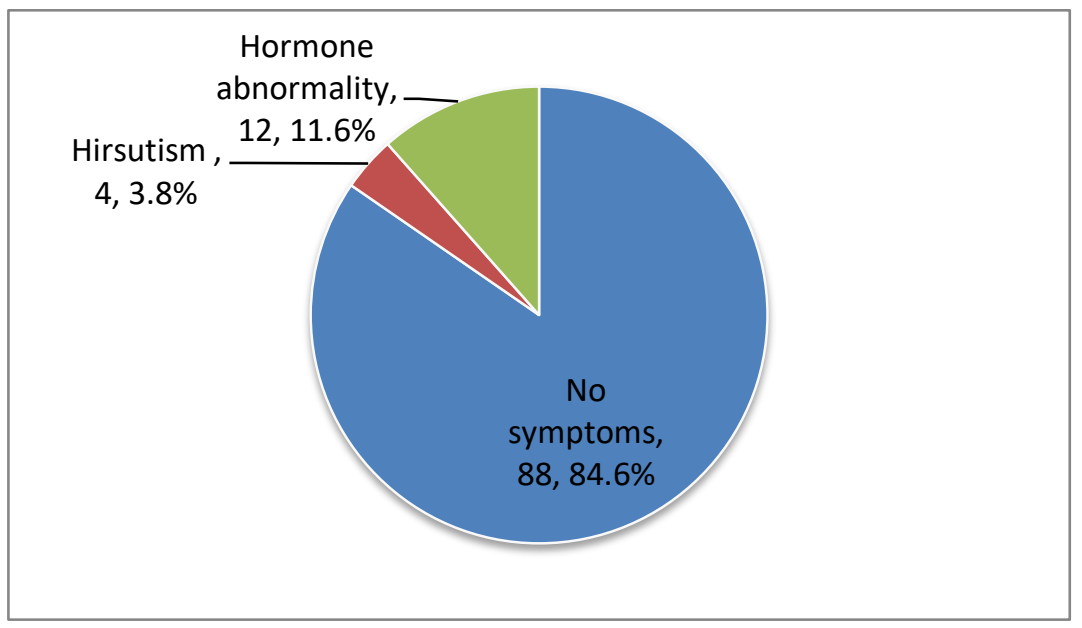

Figure 1: Distribution of participant's symptom.

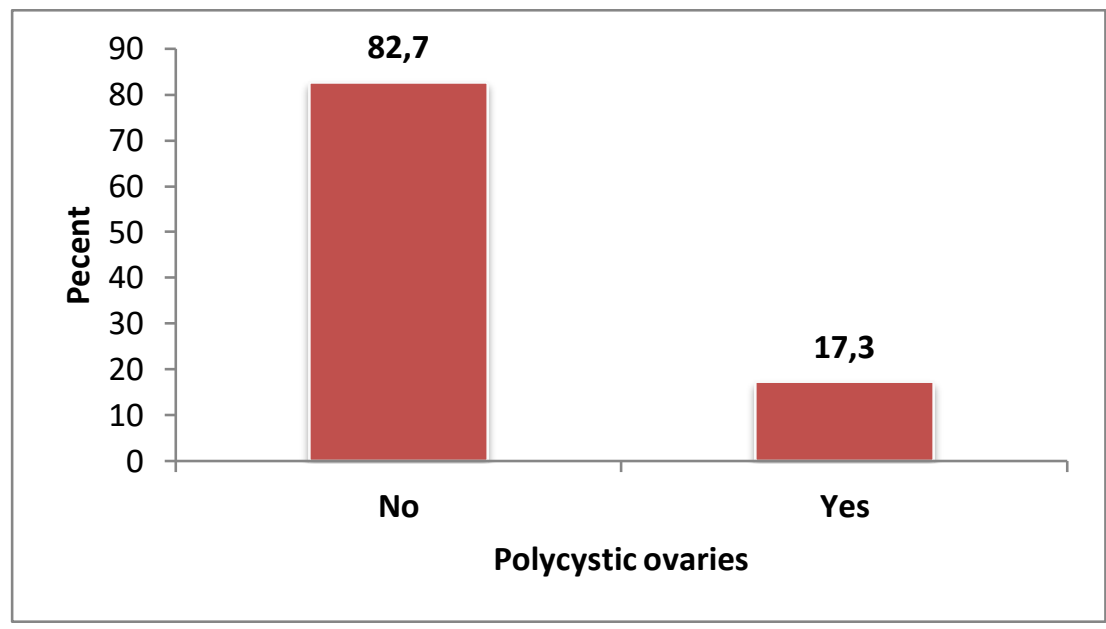

Figure 2: Distribution of polycystic ovary.

A total of 104 participants, $18(17.3 \%)$ females were diagnosed with polycystic ovarian syndrome (Figure 2). 17 (94.4\%) of women were less than 25 years-old.1(5.9\%) of them was between 25-40 years-old, and none of them shown in age more than 40 years-old, pvalue $=0.03$. All cases with PCOS have no child $18(100.0 \%)$ and this relation statistically significant $\mathrm{p}$-value $=0.01 .14(77.8 \%)$ of participants were unmarried and $4(22.2 \%)$ of them were not married, $\mathrm{p}$-value $=0.03$. In addition, majority of them were from urban residency 10 $(55.6 \%)$ followed by rural residency $8(44.4 \%)$, p-value $=0.04$. The study showed that hormonal abnormality was the most frequent symptoms in relation to polycystic ovarian syndrome $10(55.5 \%)$ followed by no hormonal abnormality $5(2738 \%)$ and few of them with hirsutism $3(16.7 \%)$, p-value $=0.001$. $10(55.6 \%)$ of women with polycystic ovarian syndrome had not family history and $8(44.4 \%)$ were with pervious family history of polycystic ovarian syndrome. Similarly, we observed that all evaluation parameters including, not doing exercise regularly, normal body weight, no thyroid problem, without using contraceptive pills and steroidal uses were 11 (61.1\%), 9 (50.0\%), 17 (94.4\%), 18 (100.0\%), 17 (94.4\%) respectively, the results were not significant $\mathrm{p}$-value $=(0.3,0.3,0.6,0.9,0.6$ respectively $)$. However, 16 
(88.9\%) of women experienced vaginal discharge and few of them without vaginal excretion 2 $(11.1 \%)$, p-value $=0.09$. (Table 2$)$

Table 2: Distribution of polycystic syndrome person characteristics and risk factors.

\begin{tabular}{|c|c|c|}
\hline Characteristics and risk factors & Number (Percent) & p-value \\
\hline \multicolumn{3}{|l|}{ Age group } \\
\hline$<25$ & 17 (94.4) & \multirow{3}{*}{0.03} \\
\hline $25-40$ & $1(5.9)$ & \\
\hline$>40$ & $0(0.0)$ & \\
\hline \multicolumn{3}{|l|}{ No of child } \\
\hline 0 & $18(100.0)$ & \multirow{3}{*}{0.01} \\
\hline $1-4$ & $0(0.0)$ & \\
\hline$>4$ & $0(0.5)$ & \\
\hline \multicolumn{3}{|l|}{ Marital states } \\
\hline Yes & $4(22.2)$ & \multirow{2}{*}{0.03} \\
\hline No & $14(77.8)$ & \\
\hline \multicolumn{3}{|l|}{ Residency } \\
\hline Urban & $10(55.6)$ & \multirow{3}{*}{0.04} \\
\hline Rural & $8(44.4)$ & \\
\hline \multicolumn{2}{|l|}{ Symptoms } & \\
\hline No & $5(27.8)$ & \multirow{3}{*}{0.001} \\
\hline Hirsutism & $3(16.7)$ & \\
\hline Hormonal abnormality & $10(55.5)$ & \\
\hline \multicolumn{3}{|l|}{ Family history } \\
\hline Yes & $8(44.4)$ & \multirow{2}{*}{0.4} \\
\hline No & $10(55.6)$ & \\
\hline \multicolumn{3}{|l|}{ Stress } \\
\hline Yes & $14(77.8)$ & 0.04 \\
\hline No & $4(22.2)$ & \\
\hline \multicolumn{3}{|l|}{ Do regular exercise } \\
\hline Yes & $7(38.9)$ & \multirow{2}{*}{0.3} \\
\hline No & $11(61.1)$ & \\
\hline \multicolumn{3}{|l|}{ Body weight } \\
\hline Normal & $9(50.0)$ & \multirow{3}{*}{0.3} \\
\hline Overweight & $4(22.2)$ & \\
\hline Underweight & $5(27.8)$ & \\
\hline \multicolumn{3}{|l|}{ Thyroid } \\
\hline Yes & $1(5.6)$ & \multirow{2}{*}{0.6} \\
\hline No & $17(94.4)$ & \\
\hline \multicolumn{3}{|l|}{ Contraceptive use } \\
\hline Yes & $0(0.0)$ & \multirow{2}{*}{0.9} \\
\hline No & $18(100.0)$ & \\
\hline \multicolumn{3}{|l|}{ Steroid uses } \\
\hline Yes & $1(5.6)$ & \multirow{2}{*}{0.6} \\
\hline No & $17(94.4)$ & \\
\hline \multicolumn{3}{|l|}{ Vaginal discharge } \\
\hline Yes & $16(88.9)$ & \multirow{2}{*}{0.09} \\
\hline No & $2(11.1)$ & \\
\hline
\end{tabular}

A total of 104 participants, 86 females were not with polycystic ovarian syndrome. $43(50.0 \%)$ of them were married and $50(50.0 \%)$ of women were unmarried, 67 (77.9\%) of them were from urban residency and $19(22.1 \%)$ from rural residency. Majority of them were <25 yearsold $64(74.4 \%)$, followed by $25-40$ years $16(18.6 \%)$. The mean age was $25.29 \pm 7.82$ years (ranged from 15 month to 50 years-old). $56(65.1 \%)$ of females have no family history of polycystic ovaries syndrome. $62(72.1 \%)$ of women not do regular exercises. $58(67.4 \%)$ of them has a normal body weight, overweight and underweight were $15(17.4 \%)$ and $13(15.2 \%)$ 
respectively. $61(70.9 \%)$ of females have no child. While, $18(20.9 \%)$ and $7(8.2 \%)$ of women have 1-4 child and more than 4 -child respectively (Table3).

Table3: Demographic personality of the non-polycystic ovarian participant

\begin{tabular}{|c|c|c|c|}
\hline \multicolumn{2}{|c|}{ Demographic personality } & \multirow[t]{2}{*}{ Number } & \multirow[t]{2}{*}{ Percent } \\
\hline Marital states & & & \\
\hline & Married & 43 & 50.0 \\
\hline & Not married & 43 & 50.0 \\
\hline \multicolumn{4}{|l|}{ Residency } \\
\hline & Rural & 19 & 22.1 \\
\hline & Urban & 67 & 77.9 \\
\hline \multicolumn{4}{|l|}{ Age group } \\
\hline & $<25$ & 64 & 74.4 \\
\hline & $25-40$ & 16 & 18.6 \\
\hline & $>40$ & 6 & 7.0 \\
\hline \multicolumn{4}{|c|}{ Family history with polycystic ovary } \\
\hline & Yes & 30 & 34.9 \\
\hline & No & 56 & 65.1 \\
\hline \multicolumn{4}{|c|}{ Do regular exercises } \\
\hline & Yes & 24 & 27.9 \\
\hline & No & 62 & 72.1 \\
\hline \multicolumn{4}{|l|}{ Body weight } \\
\hline & Normal & 58 & 67.4 \\
\hline & Overweight & 15 & 17.4 \\
\hline & Underweight & 13 & 15.2 \\
\hline \multicolumn{4}{|c|}{ Number of Child } \\
\hline & 0 & 61 & 70.9 \\
\hline & $1-4$ & 18 & 20.9 \\
\hline & $>4$ & 7 & 8.2 \\
\hline Mean age (SD) & & & \\
\hline
\end{tabular}

\section{DISCUSSION}

A total of 104 female participants were examined, and the mean age was 24.62 years, which is nearly consistence to the mean age reported by previous study [16]. 18 (17.3\%) of them were with polycystic ovary, which is nearly accordance with the study of [5]. In our study, most of the females with polycystic ovarian syndrome were less than 25 years-old and it is statistically significant, which is similar to the investigation by [6]. While, another study reported that polycystic ovarian syndrome is affecting 1 out of 15 females aged between 25-30 years-old [17].

Our results demonstrated that proportion of polycystic ovarian syndrome was higher in women from urban areas in comparison with women living in rural areas (Table2). This finding is nearly consistence to the old study which is done by Ricardo Azziz et al. who revealed that most of the polycystic ovarian syndrome patients with are expected to be in urban areas [3]. This is because of in our society; females are under depression and spend more of their times at home rather than in other places which can be considered as a significant factor for causing polycystic ovarian syndrome.

We investigated that all women with polycystic ovarian syndrome have no child. This can be an indicator of decreasing fertility with the occurrence of polycystic ovarian syndrome.

According to our results unmarried polycystic ovarian syndrome patients were more acceptable to experience polycystic ovarian syndrome when compared to married patients. It is also an agreement with earlier finding of [18] who pointed out polycystic ovarian syndrome is more common among unmarried females in comparison with married females. This could lead 
to decrease serum Leptin altitude in class of polycystic ovarian syndrome female compared to non- polycystic ovarian syndrome women [19].

In addition, our results suggested that hormonal abnormality associated to the polycystic ovarian syndrome and it is a major symptoms for detection, also follicular development or hirsutism is another suggestion, even though previous study have demonstrated significant relation between hormonal abnormality and follicular development with polycystic ovarian syndrome [14]. Since, change in the hormone especially could lead to endometrial receptivity, improving ovulatory dysfunction in polycystic ovarian syndrome and has been thought to adversely affect reproduction in female [20].

According to the stress criteria, this study modified that polycystic ovarian syndrome would related to the presence of stress and significant association was found, in which nearly consistent to the previous confirmation of raised stress and anxiety to the develop polycystic ovarian syndrome [21]

Polycystic ovarian syndrome patient's determination enhanced significantly adrenocorticotropic hormone and cortisol discharge in response to audience speak stressing, and this is apparently not mature to class differences in the hysterical response stress. However, more clear-cut hysterical stress response polycystic ovarian syndrome female, the stress induced raises in anxiety state; it was differ in the group despites raised depression. Furthermore, increasing level of serum cortisol was response to an intellectual in in polycystic ovarian syndrome women [22].

In the current study, there was no family history relation and body weight to polycystic ovarian syndrome because most cases with polycystic ovarian syndrome were without presence the expected syndrome in their families and weight relations. Previous study is nearly consistence with the result of this study in relation to body weight, this could be related to the level of fatty acid and androgenic regulation which is lead to decrease free testosterone levels, and biochemically morbid polycystic ovarian syndrome [3]. Additionally, [23] reported that the risk factors for polycystic ovarian syndrome including family history and obesity.

In our study, females with no contraceptive and steroidal uses were the most frequent and reached to peak. While, previous studies demonstrated that oral contraceptive uses benefit for treating polycystic ovarian syndrome, oral contraceptive pills were the early line management to improve clinical sgins of androgen raises for example acne and hirsutism, also help in arrangement the cycle and preventing the endometrium adjacent effects of unanimous action of estrogen [24, 25, 26].

Present results also showed that cases with polycystic ovarian syndrome were experienced more secretion of vaginal discharge. Additionally, a similar result was reported by [27].

Since, cervical mucus is the exudate through the cervical and it is a combination of vaginal exudate, cells and normal flora to form vaginal discharge, cells and flora to form vaginal discharge, this could be due to the biophysical proprieties of cervical and vaginal mucus secretion which are dependent on the hydrogel formation with the high level glycol-protein mucin 5B gene (MUC5B) and it is polymer chain reactions [28, 29].

In the current investigation, the polycystic ovarian syndrome is a frequent finding in female with a lack of physical exercise; similar result was previously reported [30]. Exercise has shown to modulate insulin sensitivity and lipid metabolism in skeletal muscle. Moreover, Exercise improves insulin sensitivity by increasing intra-myocellular triacylglycerol concentration [15]. Improvement in insulin sensitivity could be due to more efficient lipid turnover resulting in increased muscle lipid uptake, transport, utilization, and oxidation.

The literature states the efficacy of exercise training in combating metabolic syndrome in polycystic ovarian syndrome patients by marking improvements in apolipoprotein, adiponectin in the process of lipid turnover, and uptake in skeletal muscles [31].

\section{CONCLUSION}

Polycystic ovary is a major issue among females in our community; one from six females is expected to experience polycystic ovarian syndrome. Young females are probably to be at a 
high risk for developing polycystic ovarian syndrome. Despite uncertain etiology of polycystic ovarian syndrome, marital status, stress or anxiety, doing a regular exercise and pregnancy are all related parameters to the incidence of polycystic ovarian syndrome. Additionally, cases with high hormonal abnormality and vaginal excretion could be considerable indicators of polycystic ovarian syndrome. Overweight and contraceptive steroidal uses would not be highly dependent factors for polycystic ovarian syndrome suggestion.

\section{REFERENCE}

[1] The Rotterdam ESHRE/ASRM-Sponsored PCOS Consensus Workshop Group, "Revised 2003 consensus on diagnosticcriteria and long-term health risks related to polycystic ovary syndrome," Fertility and Sterility, 18 (1), pp. 41-47, 2004

[2] R. Azziz, E. Carmina, D. Dewailly, E. Diamanti-Kandarakis, H. Escobar-Morreale, W. Futterweit, et al., "POSITION STATEMENT: Criteria for Defining Polycystic Ovary Syndrome as a Predominantly Hyperandrogenic Syndrome: An Androgen Excess Society Guideline," J Clin Endocrinol Metab, 91(11), pp. 4237-4245, 2006.

[3] H. Escobar-Morreale, J. Botella-Carretero, F. lvarez-Blasco, J. Sancho, J. San Milla'n, “The Polycystic Ovary Syndrome Associated with Morbid Obesity May Resolve after Weight Loss Induced by Bariatric Surgery," J Clin Endocrinol Metab, 90 (12), pp. 6364-6369, 2005.

[4] A. Bargiota, E. Diamanti-Kandarakis, "The effects of old, new and emerging medicines on metabolic aberrations in PCOS," Ther Adv Endocrinol Metab, 3(1), pp. 27-47, 2012.

[5] R. Azziz, K. Woods, R. Reyna, T. Key, E. Knochenhauer, B. Yildiz, "The Prevalence and Features of the Polycystic Ovary Syndrome in an Unselected Population,” J Clin Endocrinol Metab, 89(6), pp. 2745-2749, 2004.

[6] T. Du, Y. Duan, K. Li, X. Zhao, R. Ni, Y. Li, D. Yang, "Statistical Genomic Approach Identifies Association between FSHR Polymorphisms and Polycystic Ovary Morphology in Women with Polycystic Ovary Syndrome," BioMed Research International, 10 (1), pp. 7, 2015.

[7] T. Zuo, M. Zhu, W. Xu, "Roles of Oxidative Stress in Polycystic Ovary Syndrome and Cancers," Oxidative Medicine and Cellular Longevity, 10 (11), pp. 14, 2016.

[8] A. Bargiota, E. Diamanti-Kandarakis, "The effects of old, new and emerging medicines on metabolic aberrations in PCOS," ther Adv Endocrinol metab., 3(1), pp. 27-47, 2012.

[9] S.Suarez1, A. Pacey, "Sperm transport in the female reproductive tract," Human Reproduction Update, 12(1) pp. 23-37, 2006.

[10] I. Gipson, R. Moccia, S. Spurr-Michaud, P. Argu, A. Gargiulo, J. Hill, G. Offner, et al., "The Amount of MUC5B Mucin in Cervical Mucus Peaks at Midcycle,” JCE \& M, 86(2), 2001.

[11] P. Vigil, M. Cortés, A. Zúñiga, J. Riquelme, F. Ceric, "Scanning Electron and Light Microscopy Study of the Cervical Mucus in Women with Polycystic Ovary Syndrome," Journal of Electron Microscopy, 58(1), pp. 21 27, 2009.

[12] O. Lunde, P. Magnus, L. Sandvik, S. Høglo, "Familial Clustering in the Polycystic Ovarian Syndrome," Gynecol Obstet Invest, 28, pp. 23-30, 1989

[13] H. Mobeen, N. Afzal, M. Kashif, "Polycystic Ovary Syndrome May Be an Autoimmune Disorder," Scientifica 10(1), pp.7, 2016.

[14] S. Doi, M. Al-Zaid, P. Towers, C. Scott, K. Al-Shoumer, "Irregular cycles and steroid hormones in polycystic ovary syndrome," Human Reproduction, 20(9), pp. 2402-2408, 2005.

[15] B. Keevil, "Steroid Mass Spectrometry for the Diagnosis of PCOS,” Med. Sci. 7, pp. 78, 2019.

[16] J.Mellembakken, S. Berga, M. Kilen, T. Tanbo, T. Abyholm, P. Fedorcsak, "Sustained fertility from 22 to 41 years of age in women with polycystic ovarian syndrome," Human Reproduction, 26(9), pp. 2499-2504, 2011.

[17] S.Qureshi, K. Shah, J. Gupta, N. Upmanyu, "Prevalence and risk factor of polycystic ovarian syndrome," Asian J Pharm Clin Res, 9(2), pp. 23-25, 2016.

[18] B. Khalaf, "Leptin levels in relation to marital status and neuroendocrine function in Iraqi females with polycystic ovary syndrome," Saudi Pharmaceutical Journal, 18, pp. 41-44, 2010.

[19] K. Remsberg, E. Talbott, J. Zborowski, R. Evans, K. McHugh-Pemu, "Evidence for competing effects of body mass, hyperinsulinemia, insulin resistance, and androgens on leptin levels among lean, overweight, and obese women with polycystic ovary syndrome," Fertil. Steril. 78, pp. 479-486, 2002.

[20] A. Shulman, Y. Ghetler, Y. Beyth and I. Ben-Nun, "The significance of an early (premature) rise of plasma progesterone in in vitro fertilization cycles induced by a "long protocol" of gonadotropin releasing hormone analogue and human menopausal gonadotropins," J Assist Reprod Genet, 13, pp. 207-211, 1996.

[21] S. Benson, P. Arck, S. Tanc, S. Hahn, K. Mann, N. Rifaie, et al., "Disturbed stress responses in women with polycystic ovary syndrome,” Psychoneuroendocrinology, 34, pp. 727-735, 2009.

[22] A. Gallinelli, M. Matteo, A. Volpe, F. Facchinetti, "Autonomic and neuroendocrine responses to stress in patients with functional hypothalamic secondary amenorrhea. Fertil. Steril, 73, pp. 812 -816, 2000.

[23] B. Shan, J.Cai, S. Yang, Z. Li, "Risk factors of polycystic ovarian syndrome among Li People," Asian Pacific Journal of Tropical Medicine, 8(7), pp. 590-593, 2015.

[24] SD. Reed, D. Scholes, AZ. LaCroix, LE. Ichikawa, WE. Barlow, SM. Ott, et al., "Longitudinal changes in bone density in relation to oral contraceptive use," Contraception, 68, pp. 177-82, 2003. 
[25] M. Gambacciani, B. Cappagli, M. Ciaponi, C. Benussi, AR. Genazzani, "Hormone replacement therapy in perimenopause: Effect of a low dose oral contraceptive preparation on bone quantitative ultrasound characteristics," Menopause, 6, pp. 43-8, 1999.

[26] M. Gambacciani, B. Cappagli, V. Lazzarini, M. Ciaponi, F. Fruzzetti, AR. Genazzani, et al., "Longitudinal evaluation of perimenopausal bone loss: Effects of different low dose oral contraceptive preparations on bone mineral density," Maturitas 54, pp. 176-80, 2006.

[27] G. Shamim, J. Stephen, C. Weliam, J. GreIndian, "The elasticity of cervical-vaginal secretions is abnormal in polycystic ovary syndrome: Case report of five PCOS women," Endocrinal Metab, 16(6), pp. 1019-1021, 2012.

[28] P. Morales, M. Roco, P. Vigil, "Human cervical mucus: relationship between biochemical characteristics and ability to allow migration of spermatozoa," Hum Reprod, 8, pp. 78-83, 1993.

[29] P. Vigil, A. Perez, J. Neira, P. Morales, "Postpartum cervical mucus: biological and rheological properties," Hum Reprod, 6, pp. 475-479, 1991.

[30] B. Chandrasekaran, "Exercise in polycystic ovarian syndrome: An evidence-based review," Saudi Journal of Sports Medicine, 17(3), pp. 123-128, 2017.

[31] SK. Hutchison, HJ. Teede, D. Rachon, CL. Harrison, BJ. Strauss, NK. Stepto, "Effect of exercise training on insulin sensitivity, mitochondria and computed tomography muscle attenuation in overweight women with and without polycystic ovary syndrome," Diabetologia, 55, pp. 1424-34, 2012. 